\title{
Tempo, História e Educação Matemática
}

\author{
Time, History, and Mathematical Education
}

Arlete de Jesus Brito*

Será que é tempo que the falta pra perceber? Será que temos esse tempo pra perder? E quem quer saber? A vida é tão rara, tão rara...

(Paciência, Lenine e Dudu Falcão)

\begin{abstract}
Resumo
Nesse artigo discutimos como a concepção de "tempo" alterou-se no decorrer da história. Analisamos de que modos tal concepção insere-se na formação do ser social, ou seja, na educação. Indicamos a necessidade de que pesquisas em História da Educação Matemática analisem como o "tempo" tem sido utilizado em Reformas Curriculares e nas práticas docentes. Nossos referenciais são Norbert Elias (1998), Michel Foucault (1993), Jacques Le Goff (1995) e Edward Thompson (1998).
\end{abstract}

Palavras-chave: Tempo. Filosofia. História. Educação. Matemática.

\begin{abstract}
In this paper, we discuss conceptions of "time" and historical changes of them. We analyze how these conceptions construct a social way of being, by education. We conclude the need for History of Mathematical Education researches about the use of the "time" in both educational laws and teaching of Mathematics. Our main references are Norbert Elias (1998), Michel Foucault (1993), Jacques Le Goff (1995) and Edward Thompson (1998).
\end{abstract}

Key-words: Time. Philosophy. History. Education. Mathematics.

Tenho por desafio apresentar, nesse tempo que nos sufoca**, um texto em que se discutam relações entre Filosofia, História e Educação Matemática. Para aceitar o desafio me impus uma condição: fazê-lo, desde que ele não seja apenas mais um texto, mas que se

\footnotetext{
"Professora livre-docente pela Universidade Estadual Paulista (UNESP). Professora dos Programas de PósGraduação em Educação e em Educação Matemática da Universidade Estadual Paulista (UNESP), Rio Claro/SP.. Endereço para correspondência: Av. 24 A, n. 1515, Bela Vista, Rio Claro/SP, CEP 13506-900. Email: arlete@rc.unesp.br

** Texto apresentado na mesa redonda do XI Encontro Nacional de Educação Matemática (XI ENEM).
} 
configure um modo de expressão de minhas atuais angústias e que sua escritura seja, para mim, um processo de transformação. Daí surgiu minha escolha, qual seja, escrever sobre o grilhão que nos aprisiona cada vez mais: o tempo, conceito que perpassa a Filosofia, a História e a Educação Matemática.

Ao se imiscuir em nossas vidas, o tempo tornou-se temática não apenas das áreas de conhecimento citadas no parágrafo anterior, mas também de outras ciências como a Física e a Sociologia, além de inspirar as artes como a música, literatura, pintura e o cinema. Por vezes, parece-nos que ele sempre existiu, ou ao menos desde que Chronos ${ }^{1}$ nasceu ou desde que Deus contou os dias da semana no ato da criação e, portanto, a nós mortais resta apenas observar sua passagem como algo natural e organizar nossas vidas segundo seus mandos.

Em diferentes sociedades, o tempo leva a criar hábitos - para alguns, sábado à noite é tempo de estar com amigos, final de ano é tempo para estar com a família, verão é tempo de ir à praia - e também disciplinariza o corpo - por exemplo, temos fome nos horários que nossas atividades diárias nos habituaram a comer. Assim, o tempo, tal qual o entendemos, faz parte da formação de nosso ser social, ou seja, de nossa educação. O tempo exerce uma coerção de fora para dentro e seu aprendizado, desde que somos crianças, colabora na construção de nossa autodisciplina. As normas sobre o tempo no fazer escolar e nos modos de trabalho têm papel primordial nessa disciplinarização, conforme Foucault,

\begin{abstract}
O horário: é uma velha herança. As comunidades monásticas haviam, sem dúvida, sugerido seu modelo estrito. Ele se difundiria rapidamente. Seus três grandes processos - estabelecer as cesuras, obrigar a ocupações determinadas, regulamentar os ciclos de repetição - muito cedo foram encontrados nos colégios, nas oficinas, nos hospitais. Dentro dos antigos esquemas, as novas disciplinas não tiveram dificuldade para se abrigar; as casas de educação e os estabelecimentos de assistência prolongavam a vida e a regularidade dos conventos de que muitas vezes eram anexos. O rigor do tempo industrial guardou durante muito tempo uma postura religiosa; no século XVII, o regulamento das grandes manufaturas precisava os exercícios que deviam escandir o trabalho (FOUCAULT, 1993, p. 136).
\end{abstract}

A partir dessa primeira digressão, nos perguntamos: o que seria o “tempo”? Há séculos, a Filosofia busca uma resposta a tal pergunta. Teorias científicas e filosóficas o apresentam como um dado natural - e o uso do substantivo "tempo" colabora para esse tipo de interpretação, pois, assim, dizemos "medir o tempo", da mesma maneira que dizemos "medir o comprimento", ou "medir a massa" -, ora colocando-o como algo independente do ser humano, como supõe a física mecânica, ora como um resultado de estruturas inatas da espécie humana e mesmo como síntese dessas duas propostas, como queria Kant (1724 1804). Kant, em seus Prolegômenos (1974) aproximava a noção de "tempo" com uma

\footnotetext{
${ }^{1}$ Chronos é o nome grego dado ao deus do tempo. A sociedade romana da Antiguidade lhe nomeou como Saturno.
} 
suposta intuição a priori transcendental que possibilitaria ao ser contar. Dessa forma, Kant observa a relação entre a contagem e a existência do tempo, mas não considera que esse último seria uma criação humana tornada possível pela invenção daquela. O desenvolvimento dos números e de suas representações, bem como dos métodos de mensuração, esteve sempre alguns passos à frente da precisão das medidas temporais e, por consequiência, da criação de instrumentos de medida e do uso sistemático da exatidão temporal nas atividades humanas. Aristóteles (sec. III a.C.), em sua obra Física já relacionava a medição do tempo à contagem:

cuando no distinguimos ningún cambio, y el alma permanece en un único momento indiferenciado, no pensamos que haya transcurrido tiempo, y puesto que cuando lo percibimos y distinguimos decimos que el tiempo ha transcurrido, es evidente entonces que no hay tiempo sin movimiento ni cambio. Luego es evidente que el tiempo no es un movimiento, pero no hay tiempo sin movimiento. [...]

Pero cuando percibimos um antes y un después, entonces hablamos de tiempo. Porque el tiempo es justamente esto: número del movimiento según el antes y después [...] Porque el tiempo es el número del desplazamiento y el ahora es, al igual que lo desplazado, como la unidad del número (ARISTÓTELES, IV, 11c).

Em sociedades antigas com rudimentares sistemas de numeração, a contagem dos ciclos da Lua era suficiente para a organização da vida social. Isso ocorria, provavelmente, porque o tipo de organização social não exigia nem um sistema complexo de numeração, nem de determinação do tempo. Segundo Le Goff (1995), na Idade Média anterior ao século XIII, não havia necessidade da exatidão na medida do tempo e a referência para sua determinação não eram os números. No Chile do século XVII, também não ocorriam grandes precisões na medição do tempo, pois este era frequentemente medido por credos: em 1647, descreveu-se que o terremoto havia durado o tempo de dois credos (cf. THOMPSON, 1998), o mesmo se observa em relação ao terremoto que abalou a cidade de Cusco, em 1650. Porém, a partir do século XIII, nas cidades comerciais da Europa, os sinos que até então marcavam apenas os ofícios religiosos, começaram a marcar também os horários do trabalho e, nos séculos XIV e $\mathrm{XV}$ com o surgimento do relógio mecânico, eles passaram a marcar aqueles horários com maior precisão. No entanto, Le Goff (1995) aponta que esses mecanismos eram frágeis, se avariavam com frequiência e o ponto de partida do dia variava de cidade para cidade, pois dependia do nascer do Sol. Porém, com o desenvolvimento da urbanização e a expansão do comércio em alguns países, essas medidas já não eram suficientes para regular a vida do homem. Assim, como observa Elias,

fez-se sentir, com intensidade cada vez maior, a necessidade de sincronizar o número crescente das atividades humanas e de dispor uma rede de referências temporais, cuja extensão regular pudesse servir de quadro de referência. Construir essa rede e fazê-la funcionar era uma das tarefas da autoridade central - clerical ou leiga. Dela dependiam o pagamento regular e periódico de impostos, dos juros e dos salários, bem como a execução de inúmeros contratos e diversos compromissos; o 
mesmo acontecia com os numerosos feriados em que as pessoas repousavam de seu trabalho (ELIAS, 1998, p. 46).

Tais necessidades de regulação das atividades sociais ocasionaram mudanças na medição do tempo como, por exemplo, quando Carlos IX, rei da França, alterou o calendário e impôs o dia primeiro de janeiro como início do ano, em 1566. Outro exemplo observável foram os diferentes modos de marcação de tempo nas igrejas de vilarejos: primeiro com toques de sinos, depois com relógios de um só ponteiro e a partir do século XVII, com relógios que marcavam horas e minutos (cf. THOMPSON, 1991). Sobre tais alterações e suas implicações nos modos de ser do homem moderno, Foucault nos diz:

Durante séculos, as ordens religiosas foram mestras de disciplina: eram os especialistas do tempo, grandes teóricos do ritmo e das atividades regulares. Mas esses processos de regularização temporal que elas [as instituições do século XIX] herdam, as disciplinas os modificam. Afinando-os primeiro. Começa-se a contar por quartos de hora, minutos, segundos. [...] Nas escolas elementares, a divisão do tempo torna-se cada vez mais esmiuçante; as atividades são cercadas o mais possível por ordens a que se tem que responder imediatamente (FOUCAULT, 1993, p. 137).

Foucault (1993, p. 137) descreve a rotina em escolas mútuas, do século XIX: "8,45 entrada do monitor, 8,52 chamada do monitor, 8,56 entrada das crianças e oração, [...] trata-se de constituir um tempo integralmente útil". Ainda hoje, o tempo é um dos conceitos utilizados para organizar o currículo escolar. Determinam-se quantas aulas as escolas devem ter por ano, por semana e por dia; em quantos anos os alunos devem ser aprovados para possuírem a escolaridade básica completa; qual a duração de cada aula; qual horário os alunos, professores e funcionários devem entrar na escola e permanecer nela; que conteúdos devem ser ensinados em cada bimestre do ano e, em alguns estados brasileiros, como por exemplo, São Paulo, determina-se até o tempo de aula em que devem ser ensinados determinados conteúdos.

A escola continua sendo um local de disciplina do corpo, por meio, inclusive, da introjeção do tempo. O que fazemos com os alunos quando determinamos horários de entrada, saída, de ir ao banheiro, os obrigamos a ficar sentados durante determinado período de tempo, senão disciplinando seus corpos? Mas, nós professores também somos disciplinados pelo tempo escolar e por isso, por exemplo, nos sentimos culpados por não conseguir "dar todo o conteúdo programado" no tempo que nos é disponível para tal. Ficamos como Hugo Cabret ${ }^{2}$, pendurados ao ponteiro do relógio e buscando alguma engenhosa saída para não cairmos na boca devoradora de um currículo famélico muito mais por disciplina do que por conhecimento.

\footnotetext{
${ }^{2}$ A invenção de Hugo Cabret (2011) foi dirigido por Martin Scorcese e co-produzido por Graham King's GK Films e Johnny Depp. É baseado em livro homônimo de Brian Selznick.
} 
Por que não nos questionamos a razão de nossas atividades serem organizadas por essa rotina temporal e não por outra? Tais rotinas são históricas, como aponta Diana Vidal e Luciano Mendes Faria Filho (2005) em capítulo do livro As lentes da história. Nele, os autores analisam as mudanças ocorridas nos horários escolares no início do século $\mathrm{XX}$, no Brasil. Segundo eles, hábitos de vida, inclusive de alimentação, precisaram ser mudados para que os alunos se adaptassem aos novos horários escolares.

Mas, apesar de toda interferência da regulação temporal sobre o currículo, não se têm pesquisas em História da Educação Matemática que analisem, com profundidade, os modos como o "tempo escolar" é mobilizado nas diferentes Reformas Curriculares, nas diversas práticas pedagógicas que ocorreram em diferentes momentos históricos e a consequente disciplina corporal advinda dessas mobilizações. Não se questiona a organização temporal escolar, as mudanças de rotina, a imposição temporal contida no currículo, nem o porquê de se ensinar a noção e a leitura do "tempo" na escola. Se há épocas atrás bastava que as crianças aprendessem a ler as horas e minutos, hoje, tal conhecimento não é mais suficiente, pois a precisão que garante a "utilidade do tempo" em nossa sociedade é, muitas vezes, da ordem de milésimos de segundo ou até menos. No entanto, o que seria o "tempo" continua uma incógnita.

Observar sociedades que não o utilizam, do mesmo modo que a nossa, ou que nem possuem um conceito de "tempo" pode nos ajudar em nossa busca por compreensões acerca dessa noção. Bourdieu (1979) realizou pesquisas com camponeses cabilas, na Argélia e segundo ele, tais camponeses possuíam uma atitude de completa indiferença em relação à passagem do tempo, a pressa era vista como falta de compostura e até mesmo como uma “ambição diabólica”. E. Thompson (1998), conta-nos dos nuers - uma confederação de tribos que vivem no sul do Sudão e no oeste da Etiópia - para os quais não existe uma expressão equivalente a "tempo" e, portanto, não podem falar dele como se fosse algo real. Os nuers organizam os acontecimentos por uma ordem lógica, não cronológica. Elias (1998) nos fala de sociedades em que não existe calendário, nelas não é possível saber, sequer, qual a idade de uma pessoa.

Nessas sociedades, cuja organização não exige uma noção de “tempo" ou, caso exija, ele não necessita ser medido com a mesma precisão que na nossa, não há um sistema simbólico (com séculos, dias, meses, horas, minutos, segundos, etc) que representem uma sucessão irreversível, no interior de um devir que não se repete, para a qual, no fim de nossas 
vidas, olhamos com descrédito e nostalgia, como o faz Krapp, personagem de Samuel Beckett ${ }^{3}$.

Nas situações em que inexiste tal sucessão, podemos buscar marcas de descontinuidade temporal. Por exemplo, em uma comunidade agrícola sem as relações de produção capitalista, o despertar pode ser determinado pelo canto do galo e a ida para lida pode não estar condicionada por um tempo específico. O tempo entre o início do trabalho e o ato de alimentar-se não é medido e o que determina esse último é a fome. O retorno do trabalho pode ser marcado tanto pelo pôr do Sol quanto pelo fim das tarefas ou mesmo pelo fim da vontade de trabalhar e não por determinado horário fixado de antemão. Nesses exemplos, ocorre uma descontinuidade temporal, pois o tempo não se apresenta contínuo, nem no que se refere a seus marcadores, nem em sua passagem, pois os acontecimentos são marcados pontualmente.

Na historiografia, vem-se discutido, há décadas, sobre as descontinuidades temporais. Em A Arqueologia do Saber (1972), Foucault afirma que o problema do historiador seria constituir séries de acontecimentos de modo a definir limites, relações e especificidades para cada um de seus elementos; elaborar séries de séries, ou seja, quadros, multiplicando estratos e mostrando a especificidade do tempo e das cronologias que lhes são próprias. Segundo esse autor, tal movimento teria ocasionado a individualização de séries diferentes que, apesar de se entrecruzarem, não podem ser reduzidas a um esquema temporal linear e, como consequiência, a noção de descontinuidade adquire um lugar importante nas disciplinas históricas. Para Le Goff (1998, p. 54), cabe ao historiador "demolir a idéia de um tempo único, homogêneo e linear. Construir conceitos operacionais dos diversos tempos de uma sociedade histórica com base no modelo de multiplicidade dos tempos sociais".

Em pesquisas anteriores (cf. MIGUEL, MIORIM e BRITO, 2013), observamos que tais discussões sobre descontinuidade têm sido abordadas em vários trabalhos de História da Educação Matemática. Porém, apesar de participar do referencial teórico, a descontinuidade não emerge na maior parte das interpretações históricas propostas por essas pesquisas, cujos textos utilizam um tempo contínuo e linear e tais interpretações não questionam os marcos temporais canônicos, como, por exemplo, "Brasil República”, "Império” e outros. Algumas pesquisas utilizam, em suas análises, pequenos períodos contínuos de tempo, o que ainda não se configura como uso do conceito de descontinuidade temporal. Portanto, elas não têm superado a idéia de continuidade temporal, nem o modelo estabelecido de medida temporal.

\footnotetext{
${ }^{3}$ A última gravação de Krapp (1958), peça de Samuel Beckett, foi publicada em 1958. Nela, o personagem título revê sua história por meio de gravações feitas por ele mesmo, em diferentes momentos sua vida.
} 
Dadas nossas vivências com o "tempo" moderno, esse padrão - em que o virar do ponteiro após a meia noite (marco historicamente instituído, pois o início de um dia já foi, conforme vimos, determinado pelo nascer do Sol) significa "mais um dia" e nunca "o dia novamente" (ideia extremamente bem explorada no filme $O$ feitiço do tempo ${ }^{4}$ ) - não é fácil de ser questionado, nem superado. Tal superação só pode ser histórica e social. No entanto, conhecer outros modos de entender o "tempo", colabora para nossas reflexões sobre ele e sobre como age na educação das pessoas na modernidade e isso pode refletir-se em nossas pesquisas.

Norber Elias, em seu livro Sobre o tempo (1998), busca uma explicação para esse conceito que sobreleve a dualidade entre os estudos que fazem dele as ciências "naturais" e a "sociais". Segundo esse autor, a

\begin{abstract}
'determinação do tempo' consiste, como dissemos, em relacionar os sucessivos aspectos apresentados por pelo menos duas séries de acontecimentos, uma das quais é socialmente padronizada para servir de padrão e medida das posições ou intervalos no interior da sucessão de acontecimentos que as outras séries comportam (ELIAS, 1998, p. 108).
\end{abstract}

Para Elias (1998), de nosso poder de observação da repetição de fenômenos naturais ${ }^{5}$ como aquele aparente do Sol e das estrelas no céu, o ritmo das marés, os batimentos do pulso, e da tomada de um desses movimentos como padrão para a medida dos demais, surgiram as primeiras ideias de passagem do tempo e suas respectivas medidas, como os primeiros calendários e relógios de sol. A partir de então, foi possível comparar processos que ocorrem sucessivamente e que, por isso, não poderiam ser diretamente comparados, como, por exemplo, o tempo de trabalho de duas pessoas cuja permanência não é concomitante, em uma indústria. Decorre disso que "sob esse ponto de vista, o conceito de tempo faz parte da mesma categoria dos símbolos utilizados pelos matemáticos. É um símbolo puramente relacional” (ELIAS, 1998, p. 107). Resulta daí que o tempo é uma síntese decorrente de nossas capacidades, socialmente aprendidas, de observar regularidades e de contar/medir. Ou seja, sem a Matemática, o tempo moderno não existiria, já que a partir da ciência moderna, o tempo foi sendo cada vez mais matematizado.

Até o início da Idade Moderna, o "tempo" era apenas um modo de sincronizar atividades sociais e não um instrumento conceitual utilizado para o estudo de fenômenos físicos, de onde advém a grande dificuldade em se discutir o conceito de velocidade, até fins

\footnotetext{
${ }^{4}$ Groundhog Day (1993). Título em português: Feitiço do Tempo. Direção Harold Ramis. Columbia Pictures Co.

${ }^{5}$ Essa observação abstrai as diferenças ocorridas em tais fenômenos. Por exemplo, o Sol não surge no mesmo horário, todos os dias. Se considerarmos, conforme propõe a astronomia, que o Universo está em expansão e que o eixo de Terra está se alterando, no decorrer de um ano, esse astro não aparecerá no céu exatamente no mesmo ponto que $\mathrm{o}$ ano anterior.
} 
da Idade Média. Até Galileu (1564 - 1642), não se imaginava utilizar o tempo para analisar um fenômeno físico. Galileu, em suas elaborações científicas sobre a aceleração e queda livre, usou como medida de tempo, a princípio, o batimento de seu pulso e, em experiências seguintes, uma clepsidra adaptada. Foi assim que o tempo passou a ser utilizado para o estudo de processos físicos, levando ao nascimento, segundo Elias (1998), do "tempo físico". A elaboração de leis "universais", em que o tempo era representado matematicamente, proveu o tempo de um estatuto de verdade eterna e imutável, tal qual aquele de que dispunha a Matemática, na época (cf. BRITO, 2005).

As investigações de Galileu sobre o pêndulo abriram uma brecha não apenas para a criação de relógios mais exatos e precisos, com marcadores para horas e minutos mecanismos inventados de modo que seu funcionamento atendesse às demandas de um "tempo" socialmente criado -, mas também para as posteriores leis de Newton (1643 - 1727). Foi assim também que o relógio, entre os séculos XVI e XVII, passou a ser o modelo para o Universo, de onde advém a expressão "Universo Mecânico". Para Foucault (1993, p. 137), “a exatidão e a aplicação são, com a regularidade, as virtudes fundamentais do tempo disciplinar".

Como já afirmamos, com os novos modos de trabalho e de sociedade surgidos a partir do capitalismo nascente, a medida do tempo precisou ser apurada para permitir a sincronização de um número de situações sociais cada vez mais complexas. $\mathrm{O}$ desenvolvimento da relojoaria - que permitiu mecanismos cada vez mais precisos de medição do tempo - contribuíram para a criação de máquinas que possibilitaram as Revoluções Industriais. Não é coincidência que o Big Ben tenha sido erigido em 1859, ou seja, em meio à segunda Revolução Industrial. O relógio, que entre os séculos XVII e XVIII forneceu um modelo ao Universo, no XIX, tornou-se um símbolo da Era Industrial. Não é sem razão que os operários das indústrias inglesas do século XIX eram proibidos de ter relógios. O controle do tempo era prerrogativa do patrão. Mas, mesmo sendo pelo relógio do patrão, as pessoas adquiriam sua própria noção de tempo e assim, o tempo penetrou o corpo. Segundo Elias (1998),

\footnotetext{
é essa uma das fontes do poder coercitivo que o "tempo" exerce sobre o indivíduo. Este é obrigado a pautar seu próprio comportamento no 'tempo' instituído pelo grupo a que pertence e, quanto mais se alongam e se diferenciam as cadeias de interdependência funcional que ligam os homens entre si, mais severa torna-se a ditadura dos relógios (ELIAS, 1998, p. 97).
}

O tempo tal qual o entendemos atualmente é resultado de uma síntese conceitual longa. Por um lado, as alterações no conhecimento científico e o desenvolvimento dos 
relógios, na Idade Moderna, contribuíram para tal síntese. Por outro, a noção moderna de tempo embasa o saber científico que foi e ainda é base para o desenvolvimento tecnológico. A Guerra sempre foi um dos maiores incentivos para tal desenvolvimento. Foi para ela o estudo da balística, nos idos anos de 1600 - que colaboraram para a formação da atual noção de tempo -, mas também a fabricação dos drones, no século XXI. O tempo $\Delta$ t do movimento de uma bala de um canhão cedeu lugar, nas novas investigações, para o tempo dt, da tecnologia da informação. Uma das principais áreas que suportam tais investigações é a Matemática. Ela, desde o início da Idade Moderna, tem sido um dos olhos do poder que se aloja nas fábricas, hospitais, na burocracia estatal, nas escolas, etc. Observa-se esse poder, por exemplo, na Inglaterra de finais do século XVIII, nos meios puritanos, em que se conclamava que a escola deveria, por meio do tempo, disciplinar o corpo das crianças pobres. Para o reverendo J. Clayton, em 1770, as crianças deveriam estar "constantemente empregadas, de algum modo, pelo menos 12 horas por dia, ganhando o seu sustento ou não" (THOMPSON, 1998, p. 292).

Nós pesquisadores da área afirmamos que ao fazer História da Educação Matemática temos, como um dos objetivos, compreender melhor o ensino e a aprendizagem atual da matemática. Como temos feito isso se passamos por cima de uma questão fundamental como a do “tempo”? Por outro lado, nós professores continuamos não explicando conteúdos em que os alunos apresentam dúvidas porque, se o fizermos, não teremos "tempo" de cumprir o currículo. Não desenvolvemos atividades alternativas em sala, porque o "tempo" de aula não permite, deixamos de lado certos conteúdos porque não temos “tempo" para trabalhá-los.

Nessa anamneses olho para o passado e vejo o presente, o meu presente. Este passado só é possível, no presente, por meio de nossas memórias, individuais ou coletivas. O que será do futuro? O futuro só é uma expectativa do indivíduo ou da sociedade. O que existe, portanto, é o presente, que acabou de se esvair nesse "tempo" que parece independer do ser humano. Elias (1998) discorre do seguinte modo sobre essa questão:

\footnotetext{
Nas sociedades urbanizadas, em especial, os relógios são produzidos e utilizados de um modo que faz lembrar a produção e utilização das máscaras em inúmeras sociedades pré-urbanas: sabe-se perfeitamente que elas são fabricadas pelos homens, mas nem por isso sua presença deixa de ser sentida como uma manifestação de uma entidade não humana. As máscaras parecem encarnar espíritos. Do mesmo modo, os relógios parecem encarnar o "tempo" (ELIAS, 1998, p. 95).
}

Damos o estatuto de existência independente dos seres humanos a algo que é uma criação social, ou, como afirma Elias (1998), uma instituição social. Esquecemos que os relógios são mecanismos historicamente criados pelas sociedades. Atualmente, tais mecanismos são feitos de modo a funcionar exatamente da mesma maneira em todas as partes 
do mundo. É isso que possibilita, por exemplo, a sincronização da bolsa de valores de New York, de Hong Kong e da BOVESPA e, por consequência, a especulação financeira.

Os relógios das igrejas medievais possuíam apenas um ponteiro e isso era suficiente para as necessidades sociais, os das fábricas da Revolução Industrial do século XVIII possuíam dois marcadores e hoje temos cronômetros que medem milésimos de segundo. Sem os conhecimentos das ciências físicas e os da Matemática, isso não seria possível. O avanço da precisão dos relógios foi acompanhado pelo aumento da autodisciplina, pois, enquanto os relógios daquelas igrejas marcavam algumas atividades sociais da comunidade, nossos relógios de pulso, atualmente, regulam todos os milésimos de segundo de nossas vidas. No entanto, não percebemos que o "tempo" só se configura para nós como uma "coisa" que existe independente de nossa sociedade, devido a essa autodisciplina aprendida desde que nascemos.

Realizamos essa "coisificação" quando nos referimos ao tempo cronológico, ao pressupormos a existência de um tempo físico, fora do ser humano. Quase não percebemos a importância, em nossa formação, do tempo kairós, que, por ser o tempo da experiência, não está dissociado do ser social. Segundo Rosa (2004), a temporalidade cronológica utilizada pela racionalidade moderna teria por especificidade neutralizar a atividade humana na temporalidade kairós que seria a da não quantificação, do não cálculo, ou seja, um "tempo" que é da ordem do sujeito e jamais enquadrável e capturado por modelações. A autora, ao discutir as teorias de Yves Schuartz acerca da atividade industriosa de trabalho, afirma que esse instante

é o da ocasião favorável - kairós - o qual não é previsto, ao contrário se decifra, se lê, na atualidade do instante. É, pois, impossível de ser transmitido porque é a própria dimensão histórica se processando, ou seja, [história] singular, dos fatos, do presente sendo feita pelo ser vivo humano nos atos de trabalho. [...] Aliás, esse 'instante', realização do kairós, é o da consecução da atividade criadora da norma e também daquelas relações dialéticas, da atividade humana. (ROSA, 2004, p. 135).

Rosa (2004) traz, pelo viés da sociologia, a discussão sobre a normatização dos trabalhadores e a resistência deles aos discursos normatizadores do trabalho, possibilitada pelo tempo da experiência, ou seja, pelo kairós. Fernandes (2011) insere, na área da História da Educação Matemática, a discussão sobre o tempo kairós na formação da memória e da experiência. A meu ver, seriam bem vindas pesquisas em Educação Matemática que buscassem revelar instantes kairós em que professores, em suas práticas docentes, têm renormatizado e resistido às normas de trabalho, inclusive as relacionadas à disciplina temporal. No entanto, independente de utilizarmos, em nossas pesquisas, o tempo cronológico ou o kairós, não podemos esquecer que ambos são uma criação social. 
Chonos e Kairós eram dois deuses gregos do tempo. Goya representa Chronos em sua obra, de inícios do século XIX, que pode ser vista no Museu do Prado ${ }^{6}$.

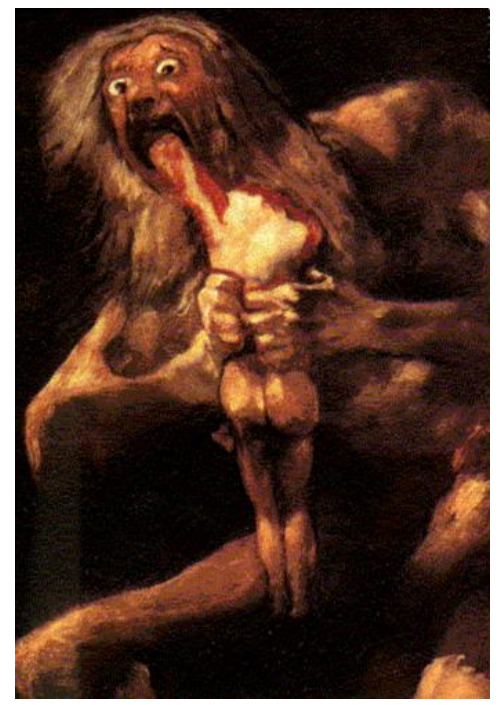

Figura 1- Saturno devorando um filho Fonte: Francisco Goya (c. 1820) / Museu do Prado

Nessa imagem, Goya representa o deus Chronos que, segundo a mitologia, devorava seus filhos - nós. Simbologia fácil de entender na superfície, mas que possibilita intermináveis discussões psicanalíticas.

O processo de reflexão ocasionado pela elaboração desse texto me deixa algumas perguntas, tais como: vamos continuar deixando que um conceito socialmente inventado, o "tempo", devore nossas experiências de vida e, inclusive, ceife nossas práticas docentes? Vamos continuar naturalizando o conceito de "tempo" em nossas pesquisas e em nossas práticas profissionais? Que mecanismos criar para resistir à disciplinarização do corpo, pelo tempo? Essas questões exigem respostas prementes, pois, afinal, a vida é tão rara!

\section{Bibliografia}

ARISTÓTELES. Física. Madrid: Editorial Gredos, 1995.

BOURDIEU, P. O desencantamento do Mundo: Estruturas Econômicas e Estruturas Temporais. São Paulo: Editora Perspectiva, 1979.

BRITO, A. J. A geometria de Euclides a Lobatschewski: um estudo histórico-pedagógico. Natal: Ed. EDUFRN, 2005.

ELIAS, N. Sobre o tempo. Rio de Janeiro: Jorge Zahar Ed., 1998.

FERNANDES, D. N. Sobre a formação do professor de matemática no Maranhão: cartas para uma cartografia possível. Rio Claro, 2011. 389

f. (Doutorado em Educação Matemática). IGCE, Unesp, Rio Claro, 2011.

\footnotetext{
${ }^{6}$ A imagem utilizada nesse texto por nós pode ser visualizada no site do google imagens.
} 
Foucault, M. A arqueologia do saber. Tradução de Luiz F. Neves. 6. ed. Rio de Janeiro: Ed. Vozes, 1972.

FOUCAULT, M. Vigiar e Punir. Tradução de Ligia M. P. Vassallo. 10. ed. Petrópolis: Ed. Vozes, 1993.

KANT, I. Prolegomenos. Coleção Pensadores. São Paulo: Abril Cultural, 1974.

LE GOFF, J. A civilização do ocidente medieval.. 2. ed. Lisboa: Ed. Estampa, 1995. v. 1.

LE GOFF, J. A história nova. 4. ed. Tradução de Eduardo Brandão. São Paulo: Martins Fontes, 1998.

MIGUEL, A.; MIORIM, M. A.; BRITO, A. J. History Of Mathematics Education In Brazil, in History of Mathematics, [Ed. UNESCOEOLSS Joint Committee], in Encyclopedia of Life Support Systems(EOLSS), Developed under the Auspices of the Unesco, Eolss Publishers, Oxford ,UK. Available at:<http://www.eolss.net>. Accessed on: 18 march 2013.

ROSA, M. I., Usos de si e testemunho de trabalhadores: com estudo crítico da Sociologia industrial e da reestruturação produtiva. São Paulo: Letras e Letras, 2004.

THOMPSON, E. P. Costumes em comum. São Paulo: Cia das Letras, 1998.

VIDAL, D. G.; e FARIA FO. L. M. Os tempos e espaços escolares no processo de institucionalização da escola primária no Brasil. In: VIDAL, D. G.; FARIA F. O. L. M. As lentes da história: estudos de história e historiografia da educação no Brasil. Campinas: Autores Associados, 2005. p. 41-72.

Submetido em Abril de 2015. Aprovado em Agosto de 2015. 